3. It seems more prudent to bold to the dynamogenetic action exercised througb the medium of the nervous system or of the circulatory system, a suppurative otitis establishing, for tbe brain, especially in patients predisposed, a permanent cause of irritation, by reflex paths. Moreover, this same inflammatory area could cause circulatory disturbances in its neighborbood or discharge into the circulation toxic products affecting the nervous system. Tbis is wby this third bypothesis, wbicb is in part analogous to that admitted by a number of alienists for hallucinations (psychosensorial theory), may perhaps be accepted, at least provisionally, until a better one replaces it.

The conclusion to be drawn, in the opinion of the author, from the perusal of tbe observations here collected and from facts that bave been individually establisbed, is.that, in a proportion of cases, in regard to the number of which it is impossible to be precise, but which certainly is too large to be neglected, the cure of otitis in certain of the insane is followed by the cure of mental disturbances. Chronic suppurative otitis being of itself a disease capable of putting life in danger, tbere is no reason for not attempting to belp a patient with an otorrbca, althougb insane, by petromastoid exenteration, if tbat is indicated. To effect a simple cure would be a bappy result; to effect a double cure would be an ideal result, and is by no means an impossibility.

\title{
PATHOIOGY AND BACTERIOLOGY.
}

\author{
UNDER THE CRARGE OY \\ SAION FLEXNER, M.D,

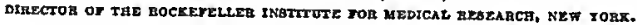

ASBIGTED BX

WARFIELD T. LONGCOPE, M.D., BEGTDE:TT PATROLOGLST, PENNG YLVANIA BOBPTTAL, PETLADELPHA.

The Effect of the Bile upon the Ester-splitting Action of Pancreatic Juice--HEWLETT (Johns Hopkins Hospial Bulletin, 1905, vol. xvi. p. 20), in a preliminary report, gives the results of some experiments which go to show tbat bile bas un accelerating influence upon the estersplitting action of pancreatic juice. By injections of secretin pancreatic juice was obtained from dogs. Tbe quantity of acid formed in twentyfour bours by the action of this juice alone upon ethyl butyrate was very small, but if bile were added the cleavage proceeded with greater rapidity, and much more acid was formed. If instead of etbyl butyrate a soluble triglyceride were employed, such as triacetin, additions of bile to the pancreatic juice exerted the same accelerating action as was noticed witb etbyl butyrate. The addition of bile also accelerates the action of pancreatic juice upon emulsion of olive oil, but to what extent has not yet been definitely determined. Furtber experiments went to sbow that of tbe various constituents of bile lecithin was the most important, and, perhaps, only substance, which possessed this accelerating 
action upon the pancreatic juice. Various suggestions may he offered to explain the inetbod of action between the hile and pancreatic juice. The author inclines to the helief, bowever, that hile, increases the ester-splitting action of the pancreatic juice hy virtue of a zymoexcitor wbich it contains; and this zymoexcitor is, at least in part, lecithin.

Adranal Rests in the Liver.-The localization of adrenal rests in the parenchyma of the kidney, along the spermatic veins, and in the neighborhood of the main genital apparatus has heen recognized, and, indeed, emphasized for some time; but apparently little attention has heen called to the presence of these structures in the liver. In an examination of $\mathbf{5 1 0}$ livers Schmorl found adrenal tissue four times, and in a fifth instance discovered an adenomatous tumor the origin of which he attributed to an adrenal rest. Obendorfer has puhlished a description of one similar tumor in the liver, while a douhtiul case has been reported by Pepère. Beer (Zeit. f. Heilkunde, 1904,'Bd. xxv. p. 381) has made a careful examination of 150 livers to determine the frequency of possible adrenal rests in this organ. In 6 of the 150 cases definite areas of adrenal tissue were found. The single masses were ahout the size of a pea. Usually the appearance was so typical that a diagnosis could be made macroscopically. They were all situated in the right lohe of the liver near the position of the adrenal gland, and all except one were placed in the capsule of Glisson. One rest was found in the parenchyma of the liver.

In this connection de Vecchi (Virch. Arch., 1904, Bd. clswii. p. 133) describes in detail a tumor about the size of a nut discovered in the liver of a man dead of pyomia following hrain ahscess. The mass lay in the right Johe of the liver at the suprarenal impression, and was hrigbt yellow in color. After careful microscopic study the author concludes that the tumor arose from an adrenal rest composed of cortical cells.

Though several theories are advanced to account for the method by which tbese portions of adrenal substance hecome incorporated in the liver, an exact explanation is still wanting.

The Protozoon of Scartet Fever.-Duval (University of Penna. Med. Bulletin, 1904, vol. xvii. p. 298) makes a preliminary report upon certain hodies found in artificial blisters produced on the skin of scarlet fever patients. For the formation of tbe "vesicle" aqua ammoniz fortior was employed. A piece of absorbent cotton, large enough to cover a circle $2 \mathrm{~cm}$. in diameter, is saturated with tbe reagent and applied to a selected skin area. In from two to five minutes tbis is removed and the area carefully smeared with vaselin. The vesicle is formed in five to six minutes, and after the vaselin has been removed with xylol the clear fluid contents, free from red blood cells and leukocytes, is withdrawn. In tbis fluid "bodies" may be found which correspond exactly to the structures descrihed by Mallory in the skin of scarlet-fever patients. The author considers these "bodies" as protozoa. They were discovered in 5 out of 18 cases of scarlet fever, but were not present in the vesicle contents of normal individuals, in the fluid from artificial vesicles produced on chemically injured skin, or in serum from artificial vesicles formed on the skin of other acute exanthemata. A full account of the work is to appear in the Archiv f. pathologische Anatomie. 